\title{
Lost in transition? Access to and uptake of adult health services and outcomes for young people with type 1 diabetes in regional New South Wales
}

\author{
Lin Perry, Katharine S Steinbeck, Janet S Dunbabin and Julia M Lowe
}

Y oung people with type 1 diabetes mellitus (TIDM) experience major life transitions in their late teens, around the time they lose access to paediatric health services. Subsequent poor engagement and early loss of contact with adult services has been linked to poorer self-management and outcomes. ${ }^{1}$

Adult diabetes services vary across geographical settings, but there has been little study of these different treatment models and their outcomes for transitioning young people. After puberty, microvascular complications increase, and continuing surveillance and optimal diabetes control are essential. ${ }^{2-4}$ Regional services are more likely to be general practitioner-led, with varied access to multidisciplinary specialists. Resource and staffing constraints are generally more pronounced in regional areas and there are few transition programs. ${ }^{5}$ Abrupt transfer of young people with TIDM from paediatric services to unfamiliar adult systems without structured preparation does little to encourage engagement. ${ }^{1,2,6-8}$

Adult diabetes services focus on self-management skills and avoidance of long-term complications, often predominantly targeting the majority population of older people with type 2 diabetes. Young people may not have the organisational skills needed to navigate the health care system, ${ }^{9}$ may experience difficulties, ${ }^{1,10}$ and may fail to connect or quickly lose contact with adult services. ${ }^{2}$ This has been linked with poorer self-management and diabetic control, resulting in early development of complications. ${ }^{4}$ Dedicated transition services have demonstrated improved outcomes. ${ }^{11}$

Given the increasing incidence of T1DM and high associated mortality, ${ }^{12}$ but a lack of information about service models, their uptake and outcomes, we audited the case notes of young people with TIDM in the state capital, a major city and a regional area of New South Wales to compare planned and unplanned service contacts and key diabetes-related indicators.

\section{METHODS}

\section{Study hypothesis and objectives}

We hypothesised that youths with TIDM in regional areas cannot access an equivalent

\section{ABSTRACT}

Objective: To document diabetes health services use and indices of glycaemic management of young people with type 1 diabetes from the time of their first contact with adult services, for those living in regional areas compared with those using city and state capital services, and compared with clinical guideline targets.

Design, setting and subjects: Case note audit of 239 young adults aged 18-28 years with type 1 diabetes accessing five adult diabetes services before 30 June 2008 in three geographical regions of New South Wales: the capital (86), a city (79) and a regional area (74).

Main outcome measures: Planned (routine monitoring) and unplanned (hospital admissions and emergency department attendance for hypoglycaemia or hyperglycaemia) service contacts; recorded measures of glycated haemoglobin $\left(\mathrm{HbA}_{1 \mathrm{c}}\right)$, body mass index (BMI), and blood pressure (BP).

Results: Routine preventive service uptake during the first year of contact with adult services was significantly higher in the capital and city. Fewer regional area patients had records of complications assessment and measurements of $\mathrm{HbA}_{1 \mathrm{c}}, \mathrm{BMI}$ and $\mathrm{BP}$ across all audited years of contact $\left(\mathrm{HbA}_{1 \mathrm{c}}: 73 \%\right.$ v 94\% city, 97\% capital; $\left.P<0.001\right)$. Across all years, regional area patients had the highest proportion of $\mathrm{HbA}_{1 \mathrm{c}}$ values $>8.0 \%(79 \% \vee 62 \%$ city, $56 \%$ capital) and lowest proportion $<7 \%$ (4\% v 7\%, 22\%) (both $P<0.001)$. Fewer young people made unplanned use of acute services for diabetes crisis management in the capital (24\% v 49\% city, 50\% regional area; $P<0.001)$. In the regional area, routine review did not occur reliably even annually, with marked attrition of patients from adult services after the first year of contact.

Conclusion: Inadequate routine specialist care, poor diabetes self-management and frequent use of acute services for crisis management, particularly in regional areas, suggest service redesign is needed to encourage young people's engagement.

MJA 2010; 193: 444-449

adult model of diabetes care after they lose eligibility to well resourced paediatric diabetes outreach services around the age of 18 years, and that this is associated with poorer diabetes control compared with youths in urban areas. We documented their health service use and indices of management, and compared them with those of cohorts attending city and state capital diabetes services, and with clinical guideline targets.

\section{Study settings and subjects}

Services were based in an ambulatory diabetes clinic at Royal Prince Alfred Hospital, Sydney (capital), the Young People's Clinic run by Hunter New England (HNE) Area Diabetes Service in Newcastle (city), and three HNE regional country towns 2-6 hours by road from Newcastle (regional area).

We aimed to audit similar-sized groups in each setting. Inclusion criteria were: a diag- nosis of T1DM, age of 18-28 years at audit, and contact with an adult service before 30 June 2008. Young people with T1DM in the capital and city were identified through clinic records. In the regional area, additional sources were required, including hospital records, a diabetes register managed by a Division of General Practice, personal records of local GPs and diabetes nurse educators (DNEs), and pathology records.

\section{Data collection}

Data were extracted during 2008 from medical files of each individual up to the study end date of 30 June 2008 by three investigators (LP, JSD and a research nurse) using a standard and previously tested form. Data extraction training included duplicate extraction to check reliability. Data spanned 1-10 years depending on the subject's age at 30 June 2008 and date of first contact with adult services. "First year" was defined as the first 
12 months after the initial contact with adult services (start date varied for each person). "All years" was defined as time from initial contact until the end date of 30 June 2008. Extracted data included demographics; planned contacts with health care professionals; hospital admissions and emergency department (ED) presentations for events attributable to hypoglycaemia or hyperglycaemia; commencement on subcutaneous insulin infusion pumps; complications assessment for retinopathy, nephropathy and neuropathy; indices of glycaemic management - glycated haemoglobin $\left(\mathrm{HbA}_{1 \mathrm{c}}\right)$, blood pressure (BP) and body mass index (BMI) - and episodes of hypoglycaemia requiring assistance. Acute service use where diabetes may have complicated management but was not the main presenting problem (eg, presentations for infection) was excluded.

Glycaemic management findings were compared with World Health Organization recommended targets:

- $\mathrm{HbA}_{1 \mathrm{c}}$ : target, <7\%; borderline, 7\%-8\%; poor, $>8 \%$;

- BP: target, systolic < $130 \mathrm{mmHg}$; diastolic $<80 \mathrm{mmHg}$;

- BMI (male): target, $<25 \mathrm{~kg} / \mathrm{m}^{2}$; borderline, $25-27 \mathrm{~kg} / \mathrm{m}^{2}$; poor, $>27 \mathrm{~kg} / \mathrm{m}^{2}$;

- BMI (female): target, $<24 \mathrm{~kg} / \mathrm{m}^{2}$; borderline, $24-26 \mathrm{~kg} / \mathrm{m}^{2}$; poor, $>26 \mathrm{~kg} / \mathrm{m}^{2}$. ${ }^{13}$

\section{Statistical analysis}

Statistical analyses were performed using SPSS for Windows, version 17 (SPSS Inc, Chicago, Ill, USA), with a $5 \%$ level of significance. Where family-wise tests indicated significant difference (reported in tables), pair-wise tests with Bonferroni correction $(P<0.017)$ were applied (reported in text). $\chi^{2}$ or Fisher exact tests were used for categorical data; one-way analysis of variance and Student's $t$ test, or Kruskal-Wallis $\mathrm{H}$ and Wilcoxon Mann-Whitney tests were used for ordinal and interval data.

Retention of young people in contact with services was calculated in two ways: 1) all study subjects eligible by age in each location at each time point; and 2) all those eligible by age minus those whose subsequent ongoing non-attendance suggested they had permanently relocated (we could not verify whether those who ceased attending had moved away).

\section{Ethical considerations}

The audit was part of a broader study for which approval was granted by relevant health services and university human

1 Demographic and clinical characteristics of 239 young people with type 1 diabetes mellitus in selected regional, city and state capital health services in New South Wales, 2008*

\begin{tabular}{lcccc} 
& $\begin{array}{c}\text { Regional } \\
(n=74)\end{array}$ & $\begin{array}{c}\text { City } \\
(n=79)\end{array}$ & $\begin{array}{c}\text { Capital } \\
(n=86)\end{array}$ & $P$ \\
\hline Female & $32(43 \%)$ & $42(53 \%)$ & $40(47 \%)$ & 0.554 \\
Aboriginal or Torres Strait Islander & 8 & 1 & 1 & \\
Age at audit, mean (SD) years & $23.1(2.7)$ & $21.4(2.0)$ & $23.7(3.0)$ & $<0.001$ \\
Age at first contact with adult services, & $20.1(2.4)$ & $18.3(1.4)$ & $21.0(2.9)$ & $<0.001$ \\
mean (SD) years & & & & \\
Years of adult service use, median (IQR) & $2.8(1.9-4.6)$ & $3.2(2.1-5.1)$ & $2.2(1.2-4.9)$ & 0.385 \\
Duration of diabetes, median (IQR) years & $12(7-17)$ & $11(8-14)$ & $10(4-14)$ & 0.040 \\
Diagnosed in 2 years before audit & 5 & 0 & 17 & \\
Diagnosed as adult & 11 & 0 & 28 & \\
Moved into area as adult & 5 & 0 & 0 & \\
${\text { BMI }>\text { 25 kg/m }{ }^{2} \text { in first year }}^{\dagger}$ & $20(27 \%)$ & $36(46 \%)$ & $41(48 \%)$ & \\
HbA $_{1 c}$ in first year of contact with adult & $9.4 \%$ & $8.7 \%$ & $8.4 \%$ & 0.032 \\
services, median (IOR) & $(7.9 \%-11.0 \%)$ & $(7.7 \%-10.1 \%)$ & $(7.2 \%-10.2 \%)$ & \\
Insulin pump started in first year & 2 & 5 & 10 & \\
\hline
\end{tabular}

$\mathrm{IQR}=$ interquartile range. $\mathrm{BMI}=$ body mass index. $\mathrm{HbA}_{1 \mathrm{c}}=$ glycated haemoglobin. ${ }^{\star}$ Figures are number or number (\%) of subjects unless otherwise indicated. † For both sexes.

research ethics committees; ethics committee approval was not required for this component. Local Audit Office approvals were granted.

\section{RESULTS}

\section{Characteristics of service users}

We identified 286 young people aged 18-28 years at 30 June 2008 and audited the records of 240 (84\%). We audited records of all eligible subjects in the regional area $(n=74)$, after excluding 27 young people identified in records of paediatric services but for whom no record of contact with adult services was found. To obtain similar-sized groups in each area, we randomly sampled 80 young people from the city clinic database of 108; one patient who died from diabetic ketoacidosis before adult service uptake was audited but excluded from analysis $(n=79,73 \%)$. Of the 104 eligible subjects in the capital, we audited all available case notes ( $n=86,83 \%)$. Across all settings, most patients (200/286, 70\%) had attended paediatric services. Demographic and clinical characteristics of the 239 young people included in our analyses are shown in Box 1.

\section{Planned adult service use}

Recorded contact with doctors and DNEs differed significantly between groups in both the first year and all years (Box 2; all $P<0.001)$. For annual complications screening in the first year, seven (9\%), 12 (15\%) and 38 (44\%) of the regional, city and capital subjects, respectively, had all three assessments of retinal, renal and foot health. Proportions having each assessment were significantly higher in the capital $(P<0.001)$ (Box 2). In both the first year and all years, total planned service use was significantly lower in the regional area than in the city and capital $(P<0.001)$. Recorded service contacts in the two urban areas did not differ significantly in either period. Significantly more missed appointments were recorded in the city in the first year: in the regional, city and capital cohorts, 18, 43 and 14 people missed 34, 86 and 18 appointments, respectively. This pattern held across all years (Box 2).

Both methods of examining retention of young people's contact with services demonstrated marked early attrition in the regional cohort, with better longer-term retention of the capital cohort (Box 3). Numbers were small but, for example, 13, 7 and 12 young people appeared to still be resident in regional, city and capital areas, respectively, in Year 7, with 8, 2 and 10 of these young people in contact with their services that year.

\section{Monitoring glycaemic control}

Routine monitoring of indices of glycaemic management (BMI, BP, $\mathrm{HbA}_{1 \mathrm{c}}$ ) was recorded 
2 Recorded planned health service contacts of 239 young people with type 1 diabetes mellitus a) during their first year and b) during all years of contact with adult health services*

\begin{tabular}{|c|c|c|c|c|}
\hline Recorded service contacts & $\begin{array}{l}\text { Regional } \\
(n=74)\end{array}$ & $\begin{array}{c}\text { City } \\
(n=79)\end{array}$ & $\begin{array}{l}\text { Capital } \\
(n=86)\end{array}$ & $P$ \\
\hline \multicolumn{5}{|l|}{ a) First year } \\
\hline Consulted a doctor & $28(38 \%)$ & 77 (97\%) & 77 (90\%) & $<0.001$ \\
\hline Consultations with doctor, median (IQR) & $0(0-1)$ & $3(1-4)$ & $2(1-3)$ & $<0.001$ \\
\hline Consulted a DNE & 55 (74\%) & 77 (97\%) & $81(94 \%)$ & $<0.001$ \\
\hline Consultations with DNE, median (IQR) & $1(0-3)$ & $3(2-4)$ & $4(1-7)$ & $<0.001$ \\
\hline Consulted a dietitian & $44(59 \%)$ & 55 (70\%) & $55(64 \%)$ & 0.420 \\
\hline Consultations with dietitian, median (IQR) & $1(0-1)$ & $1(0-2)$ & $1(0-2)$ & 0.213 \\
\hline Retinal assessment & $20(27 \%)$ & $17(22 \%)$ & 49 (57\%) & $<0.001$ \\
\hline Renal function assessment & $30(41 \%)$ & $21(27 \%)$ & $50(58 \%)$ & $<0.001$ \\
\hline Foot check & $12(16 \%)$ & $22(28 \%)$ & $43(50 \%)$ & $<0.001$ \\
\hline Any planned service contacts, ${ }^{\dagger}$ median (IQR) & $4(2-8)$ & $9(6-12)$ & $10(5-15)$ & $<0.001$ \\
\hline Missed one or more appointments & $18(24 \%)$ & $43(54 \%)$ & $14(16 \%)$ & $<0.001$ \\
\hline \multicolumn{5}{|l|}{ b) All years (range, 1-10 years) } \\
\hline Consulted a doctor & $38(51 \%)$ & $78(99 \%)$ & $80(93 \%)$ & $<0.001$ \\
\hline Consultations with doctor, median (IQR) & $1(0-2)$ & $5(3-10)$ & $3(2-6)$ & $<0.001$ \\
\hline Consulted a DNE & $60(81 \%)$ & 78 (99\%) & $81(94 \%)$ & $<0.001$ \\
\hline Consultations with DNE, median (IQR) & $2(1-4)$ & $5(3-11)$ & $6(3-16)$ & $<0.001$ \\
\hline Consulted a dietitian & $54(73 \%)$ & $64(81 \%)$ & $65(76 \%)$ & 0.484 \\
\hline Consultations with dietitian, median (IQR) & $1(0-2)$ & $2(1-3)$ & $1(1-3)$ & 0.046 \\
\hline Retinal assessment & $23(31 \%)$ & 42 (53\%) & $58(67 \%)$ & $<0.001$ \\
\hline Renal function assessment & $39(53 \%)$ & $49(62 \%)$ & $60(70 \%)$ & $<0.001$ \\
\hline Foot check & $17(23 \%)$ & $50(63 \%)$ & $50(58 \%)$ & $<0.001$ \\
\hline Any planned service contacts, ${ }^{\dagger}$ median (IQR) & $7(3-12)$ & $17(9-33)$ & $16(9-34)$ & $<0.001$ \\
\hline Missed one or more appointments & $30(41 \%)$ & 69 (87\%) & $32(37 \%)$ & $<0.001$ \\
\hline
\end{tabular}

$\mathrm{IQR}=$ interquartile range. $\mathrm{DNE}=$ diabetes nurse educator. ${ }^{*}$ Figures are number or number (\%) of subjects unless otherwise indicated. † Consultations with doctor, DNE, dietitian, podiatrist or ophthalmologist.

3 Proportions of young people contacting adult health services at least once a year in each of the first 6 years of contact, estimated in two different ways

$$
\text { Regional area } \square \text { City } \square \text { Capital }
$$

A

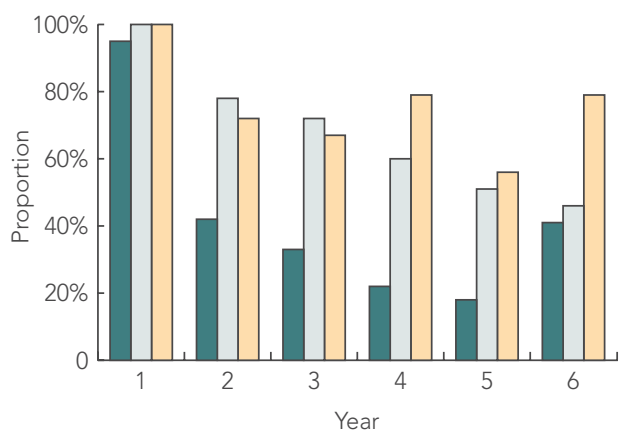

B

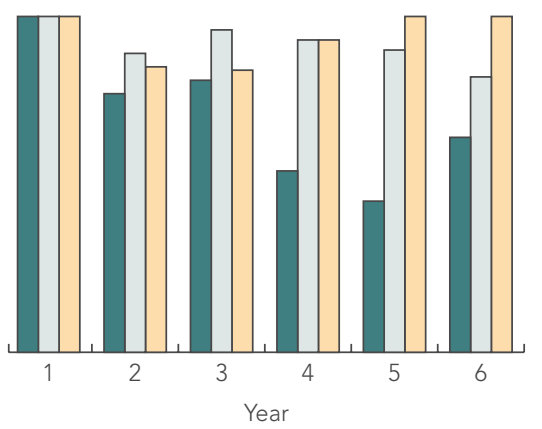

A: The total eligible according to their age at each time point. B: Those eligible by age but excluding those thought to have moved away from the area.

significantly less frequently for regional than urban young people, in both the first year and all years $(P<0.001)$ (Box 4$)$. At least one $\mathrm{HbA}_{1 \mathrm{c}}$ reading was recorded for 199 of the 239 service users (83\%) in their first year of contact with an adult service, with these individuals having between one and seven measurements. In the first year, 20 (27\%), $68(86 \%)$ and $64(74 \%)$ of the regional, city and capital subjects, respectively, had all three measurements of $\mathrm{HbA}_{1 \mathrm{c}}$, $\mathrm{BP}$ and BMI recorded.

\section{Unplanned acute service use for hypoglycaemia or hyperglycaemia}

Overall, there was significantly less unplanned service use for hypoglycaemia or hyperglycaemia by the capital cohort compared with the regional cohort in the first year $(P=0.010)$ and compared with both the regional $(P=0.002)$ and city $(P<0.001)$ cohorts in all years (Box 4). However, across all years, there were significantly more ED presentations in the city compared with the regional area $(P=0.014)$ or the capital $(P<0.001)$, with significantly fewer episodes of hospital admission in the capital than elsewhere $(P=0.011 \mathrm{v}$ city, $P=0.001 \mathrm{v}$ regional area).

\section{Indices of glycaemic management}

Median $\mathrm{HbA}_{1 \mathrm{c}}$ values in the first year were $9.4 \%, 8.7 \%$ and $8.4 \%$ in the regional area, city and capital, respectively (Box 1). Comparing values with targets recommended by the World Health Organization, ${ }^{13}$ all areas had substantial numbers of recorded $\mathrm{HbA}_{1 \mathrm{c}}$ values indicative of borderline or poor glycaemic control, but there was a consistent pattern in the first year and all years of better $\mathrm{HbA}_{1 \mathrm{c}}$ values among the capital cohort compared with generally poorer control among young people in the regional area (Box 5). Of a total of $467 \mathrm{HbA}_{1 \mathrm{c}}$ measurements retrieved for all three cohorts for the first year, 62 (13\%) were $<7 \%, 111(24 \%)$ were $7 \%-8 \%$, and 294 (63\%) were > 8\%. A similar pattern was seen with the 1202 measurements retrieved across all years, of which 161 (13\%) were $<7 \%$, $307(26 \%)$ were $7 \%-8 \%$, and $734(61 \%)$ were $>8 \%$. In all years, the regional cohort had significantly more recorded values $>8 \%$ and fewer $<7 \%$ than the capital cohort (both $P<0.001$ ). Substantial proportions of all cohorts nevertheless experienced at least one hypoglycaemic event requiring assistance (Box 4).

\section{DISCUSSION}

This study is the first in Australia to examine disparate facets of care for young people with TIDM beyond the age of eligibility to use paediatric services. Different service configurations and resources in the three geographical settings were reflected in clear 
4 Recorded glycaemic management and unplanned acute service use for hypoglycaemia or hyperglycaemia of 239 young people with type 1 diabetes mellitus a) during their first year and b) during all years of contact with adult health services*

\begin{tabular}{|c|c|c|c|c|}
\hline & Regional $(n=74)$ & City $(n=79)$ & apital $(n=86)$ & $P$ \\
\hline \multicolumn{5}{|l|}{ a) First year } \\
\hline $\mathrm{HbA}_{1 \mathrm{c}}$ documented & $46(62 \%)$ & $72(91 \%)$ & $81(94 \%)$ & $<0.001$ \\
\hline $\mathrm{HbA}_{1 \mathrm{c}}$ assessments, median (IQR) & $1(0-2)$ & $3(1-4)$ & $2(1-3)$ & $<0.001$ \\
\hline Blood pressure (BP) documented & $31(42 \%)$ & $73(92 \%)$ & $70(81 \%)$ & $<0.001$ \\
\hline BP assessments, median (IQR) & $0(0-1)$ & $3(1-4)$ & $1(1-2)$ & $<0.001$ \\
\hline BMI documented & $34(46 \%)$ & 70 (89\%) & 77 (90\%) & $<0.001$ \\
\hline BMI assessments, median (IQR) & $0(0-1)$ & $3(1-4)$ & $2(1-4)$ & $<0.001$ \\
\hline $\begin{array}{l}\text { Hypoglycaemic episodes requiring } \\
\text { assistance }\end{array}$ & $8(11 \%)$ & $12(15 \%)$ & $14(16 \%)$ & 0.285 \\
\hline Admitted to hospital ${ }^{\dagger}$ & $26(35 \%)$ & $18(23 \%)$ & $11(13 \%)$ & 0.027 \\
\hline Hospital admission episodes ${ }^{\dagger}$ & 43 & 32 & 11 & 0.001 \\
\hline Attended $\mathrm{ED}^{\dagger}$ & $4(5 \%)$ & $11(14 \%)$ & $6(7 \%)$ & 0.458 \\
\hline ED attendance episodes ${ }^{\dagger}$ & 5 & 19 & 8 & 0.122 \\
\hline Total unplanned service attendees ${ }^{\ddagger}$ & $28(38 \%)$ & $26(33 \%)$ & $15(17 \%)$ & 0.046 \\
\hline Total unplanned service use episodes ${ }^{\ddagger}$ & 48 & 51 & 19 & 0.007 \\
\hline \multicolumn{5}{|l|}{ b) All years (range, 1-10 years) } \\
\hline $\mathrm{HbA}_{1 \mathrm{c}}$ documented & $54(73 \%)$ & $74(94 \%)$ & $83(97 \%)$ & $<0.001$ \\
\hline $\mathrm{HbA}_{1 \mathrm{c}}$ assessments, median (IQR) & $1(0-3)$ & $5(2-10)$ & $4(2-7)$ & $<0.001$ \\
\hline BP documented & $39(53 \%)$ & $75(95 \%)$ & 75 (87\%) & $<0.001$ \\
\hline BP assessments, median (IQR) & $1(0-1)$ & $5(3-10)$ & $3(1-6)$ & $<0.001$ \\
\hline BMI documented & $42(57 \%)$ & $72(91 \%)$ & 79 (92\%) & $<0.001$ \\
\hline BMI assessments, median (IQR) & $1(0-2)$ & $5(2-11)$ & $3(2-7)$ & $<0.001$ \\
\hline $\begin{array}{l}\text { Hypoglycaemic episodes requiring } \\
\text { assistance }\end{array}$ & $14(19 \%)$ & $17(22 \%)$ & $21(24 \%)$ & 0.449 \\
\hline Admitted to hospital ${ }^{\dagger}$ & $32(43 \%)$ & $29(37 \%)$ & $17(20 \%)$ & $<0.001$ \\
\hline Hospital admission episodes ${ }^{\dagger}$ & 82 & 79 & 19 & 0.004 \\
\hline Attended $\mathrm{ED}^{\dagger}$ & $10(14 \%)$ & $24(30 \%)$ & $7(8 \%)$ & 0.010 \\
\hline ED attendance episodes ${ }^{\dagger}$ & 29 & 56 & 11 & $<0.001$ \\
\hline Total unplanned service attendees ${ }^{\ddagger}$ & 37 (50\%) & $39(49 \%)$ & $21(24 \%)$ & $<0.001$ \\
\hline Total unplanned service use episodes ${ }^{\ddagger}$ & 111 & 135 & 30 & $<0.001$ \\
\hline
\end{tabular}

$\mathrm{HbA}_{1 \mathrm{c}}=$ glycated haemoglobin. $\mathrm{IQR}=$ interquartile range. $\mathrm{BMI}=$ body mass index. $\mathrm{ED}=$ emergency department. * Figures are number or number (\%) of subjects unless otherwise indicated. †For hypoglycaemia or hyperglycaemia. $¥$ All hospital admissions and ED attendance for hypoglycaemia or hyperglycaemia.

patterns across the audited period. There was limited access to adult services and contact with specialist staff in the regional area, with many young people not receiving any reviews each year. Acute hospital services were used for crisis management in all settings, but much less frequently in the capital. Despite elevated $\mathrm{HbA}_{1 \mathrm{c}}$ values in all areas, many young people experienced episodes of severe hypoglycaemia. Service practices limited our ability to identify loss to contact between paediatric and adult services, but attrition from adult services appeared to be around $50 \%$ by 5 years, and complications screening. By contrast, as previously reported, ${ }^{5,15}$ regional diabetes services had fewer resources, heavier reliance on GPs and limited access to specialists. Distance and geographical socioeconomic factors have been acknowledged as major issues in access to diabetes services, and strong predictors of attendance. ${ }^{2}$

Our findings contrast with a report of paediatric patients in NSW, which found no difference in the metabolic control of rural and urban children (median $\mathrm{HbA}_{1}, 8.2 \%$ in both). ${ }^{16}$ Median $\mathrm{HbA}_{1 \mathrm{c}}$ values in our three cohorts, particularly in the regional area, were substantially higher, highlighting the challenges of chronic disease self-management in early adulthood ${ }^{1}$ and the deterioration in control that occurs when young people leave the comprehensive paediatric rural outreach clinics.

Overall, we found that recorded routine service delivery fell short of that advocated in national and international guidance. ${ }^{4,13,17}$ National recommendations stipulate no less than 3-4 reviews per year for adolescents; ${ }^{4}$ adult T1DM guidelines have not been established, but we found that not even annual review was always achieved in the regional area. Potentially avoidable acute service use for crisis management represents opportunity costs that could be invested to redesign services to better meet the needs of this group.

All three settings showed evidence of poor glycaemic control. The capital service had the greatest proportion of recently diagnosed users, whose "honeymoon phase" values may have contributed to greater numbers of $\mathrm{HbA}_{1 \mathrm{c}}$ readings within target ranges. However, our findings are comparable with other studies of adolescents and young adults from Australia and elsewhere. $3,11,18$ The risk of progression to severe diabetic retinopathy in the Diabetes Control and Complications Trial follow-up study was reduced by $78 \%$ in the group originally treated intensively, demonstrating the longer-term value of good control. ${ }^{19}$ Services should consider ways to make access easier for young people and to maintain contact, as this provides the best chance of achieving better control, given that deterioration in diabetes indices around this age seems common. ${ }^{1}$ The poor retention rates demonstrated in our study and others indicate this is not occurring. ${ }^{2,7,20}$

Our findings suggest a likely mix of developmental characteristics of youth and system failures of current service models to engage, retain and support these young people. The Newcastle and Sydney services 
5 Comparison of young people's glycaemic management audit data from the first year and all years of contact with adult health services (to 30 June 2008) with World Health Organization recommended targets ${ }^{13 *}$

\begin{tabular}{|c|c|c|c|c|c|}
\hline & Period & Regional & City & Capital & $P$ \\
\hline \multicolumn{6}{|l|}{ Blood pressure $(\mathrm{mmHg})$} \\
\hline \multirow[t]{2}{*}{$<130 / 80^{\dagger}$} & First year & $34(81 \%)$ & $83(40 \%)$ & $106(80 \%)$ & $<0.001$ \\
\hline & All years & $53(74 \%)$ & 245 (47\%) & 342 (84\%) & $<0.001$ \\
\hline \multirow[t]{2}{*}{$\geqslant 130 / 80$} & First year & $8(19 \%)$ & $124(60 \%)$ & $26(20 \%)$ & $<0.001$ \\
\hline & All years & $19(26 \%)$ & 281 (53\%) & $66(16 \%)$ & $<0.001$ \\
\hline \multicolumn{6}{|l|}{ Body mass index $\left(\mathrm{kg} / \mathrm{m}^{2}\right)$} \\
\hline \multirow[t]{2}{*}{$<25$ (men), $<24$ (women) $)^{\dagger}$} & First year & $26(43 \%)$ & $106(48 \%)$ & 117 (54\%) & $<0.001$ \\
\hline & All years & $43(44 \%)$ & 262 (47\%) & $215(45 \%)$ & $<0.001$ \\
\hline \multirow[t]{2}{*}{ 25-27 (men), 24-26 (women) } & First year & $11(18 \%)$ & $54(24 \%)$ & $43(20 \%)$ & 0.022 \\
\hline & All years & $16(16 \%)$ & 163 (29\%) & $81(17 \%)$ & 0.001 \\
\hline \multirow[t]{2}{*}{$>27$ (men), > 26 (women) } & First year & $24(39 \%)$ & $61(28 \%)$ & $55(26 \%)$ & 0.156 \\
\hline & All years & $39(40 \%)$ & 135 (24\%) & $178(38 \%)$ & 0.060 \\
\hline \multicolumn{6}{|l|}{$\mathrm{HbA}_{1 \mathrm{c}}$} \\
\hline \multirow[t]{2}{*}{$<7 \%^{\dagger}$} & First year & $6(8 \%)$ & $18(9 \%)$ & $38(20 \%)$ & 0.002 \\
\hline & All years & $6(4 \%)$ & $39(7 \%)$ & $116(22 \%)$ & $<0.001$ \\
\hline \multirow[t]{2}{*}{$7 \%-8 \%$} & First year & 14 (18\%) & 53 (27\%) & 44 (23\%) & 0.005 \\
\hline & All years & 24 (17\%) & 168 (31\%) & 115 (22\%) & $<0.001$ \\
\hline \multirow[t]{2}{*}{$>8 \%$} & First year & 58 (74\%) & $129(65 \%)$ & 107 (57\%) & 0.001 \\
\hline & All years & 112 (79\%) & 332 (62\%) & 290 (56\%) & $<0.001$ \\
\hline
\end{tabular}

$\mathrm{HbA}_{1 \mathrm{c}}=$ glycated haemoglobin. * Figures are number (\%) of total recorded values for each index of glycaemic management. † WHO recommended target.

included specialised clinics for young adults, and all centres stated they were proactive in following up patients who failed to attend. However, neither strategy appears to have solved the retention problem. More important may be the manner in which clinics are run. Transitional services that address young people's priorities and lifestyle requirements can sustain users' engagement with services, lower drop-out rates, improve uptake of educative and preventive services, ${ }^{21,22}$ and improve diabetic control. ${ }^{8,11}$ Innovative examples such as the Maestro Project in Canada, ${ }^{22}$ which used a case management approach to service coordination and social educational networking, have shown this is achievable for young people in regional areas.

Our study has some limitations. The sample sizes of our groups were small, and a documentation audit only shows what was recorded and may not reflect user and stakeholder experiences. Any service redesign would need to take into account what service users say would be useful to help them achieve better long-term diabetes control. Auditing was particularly problematic where regional service records were fragmented and hard to access, and in general practice.
Although our study found key indices of diabetes management were poor in all settings, there was substantially lower access to and uptake of routine monitoring and preventive services in regional compared with urban settings. In regional areas, adolescents transfer from multidisciplinary "one-stop shop" paediatric outreach clinics to very differently configured adult diabetes services, and attrition is high. Coaching is needed to prepare young people for these changes, as well as improvements in service coordination and appointment of case managers to help them navigate adult care. Specialist diabetes health care professionals are in short supply, and GPs need to be supported to develop TIDM expertise. Our findings do not support continuance of the status quo and suggest service reconfiguration is needed, to ensure equity of access for the small but increasing numbers of young people with TIDM in regional Australia and to achieve acceptable outcomes for all Australians with TIDM.

\section{ACKNOWLEDGEMENTS}

We thank the staff of Royal Prince Alfred Hospital, Sydney, and Hunter New England Area Health Service for their support with data access and collection. The study was funded by the NSW Institute of Rural Clinical Services and Teaching.

\section{COMPETING INTERESTS}

None identified.

\section{AUTHOR DETAILS}

Lin Perry, PhD, MSc, RN, Professor of Nursing ${ }^{1}$ Katharine S Steinbeck, MB BS, FRACP, PhD, Medical Foundation Chair in Adolescent Medicine ${ }^{2}$

Janet S Dunbabin, BAg(Sc), PhD, Research Assistant $^{3}$

Julia M Lowe, MB ChB, FRCP, MMedSci,

Associate Professor ${ }^{4}$

1 Faculty of Nursing Midwifery and Health,

University of Technology Sydney, Sydney, NSW.

2 University of Sydney, Sydney, NSW.

3 Newcastle Institute of Public Health,

University of Newcastle, Newcastle, NSW.

4 Department of Endocrinology, Sunnybrook

Health Sciences Centre, Toronto, Ontario,

Canada.

Correspondence: Lin.Perry@uts.edu.au

\section{REFERENCES}

1 Fleming E, Carter B, Gillibrand W. The transition of adolescents with diabetes from the children's health care service into the adult health care service: a review of the literature. $J$ Clin Nurs 2002; 11: 560-567.

2 Kipps S, Bahu T, Ong K, et al. Current methods of transfer of young people with Type 1 diabetes to adult services. Diabet Med 2002; 19: 649654.

3 Barton DM, Baskar V, Kamalakannan D, et al. An assessment of care of paediatiric and adolescent patients with diabetes in a large district general hospital. Diabet Med 2003; 20: 394-398.

4 Australasian Paediatric Endocrine Group. Clinical practice guidelines: type 1 diabetes in children and adolescents. Canberra: National Health and Medical Research Council, 2005. http://www.nhmrc.gov.au/publications/synopses/cp102syn.htm (accessed Aug 2009).

5 Lister S, Brodie L. Transition Care Workforce Project. Final report: November 2008. Sydney: Greater Metropolitan Clinical Taskforce Transition Care Network, 2008. http://www.health. nsw.gov.au/resources/gmct/transition/pdf/ transition_care_workforce_report.pdf (accessed Aug 2009).

6 Pacaud D, Yale J-F, Stephure D, et al. Problems in transition from pediatric care to adult care for individuals with diabetes. Can J Diabetes 2005; 29: 13-18.

7 Busse FP, Hiermann P, Galler A, et al. Evaluation of patients' opinion and metabolic control after transfer of young adults with type 1 diabetes from a pediatric diabetes clinic to adult care. Horm Res 2007; 67: 132-138.

8 Cadario F, Prodam F, Bellone S, et al. Transition process of patients with type 1 diabetes (T1DM) from paediatric to the adult health care service: a hospital-based approach. Clin Endocrinol (Oxf) 2009; 71: 346-350. 
9 Diabetes Australia. National review of transitional care. Canberra: Diabetes Australia, 2007. http://www.diabetesaustralia.com.au/PageFiles/5928/National\%20Review\%20of\%20Trans itional\%20Care\%20Report.pdf (accessed Aug 2009).

10 Olsen R, Sutton J. More hassle, more alone: adolescents with diabetes and the role of formal and informal support. Child Care Health Dev 1998; 24: 31-39.

11 Holmes-Walker DJ, Llewellyn AC, Farrell K. A transition care programme which improves diabetes control and reduces hospital admission rates in young adults with Type 1 diabetes aged 15-25 years. Diabet Med 2007; 24: 764-769.

12 Australian Institute of Health and Welfare. Insulin-treated diabetes in Australia 2000-2007. Canberra: AlHW, 2009. (AlHW Cat. No. CVD 45; Diabetes series no. 11.) http://www.aihw.gov. au/publications/cvd/cvd-45-10728/cvd-4510728.pdf (accessed Aug 2009).

13 Khatib OMN, editor. Guidelines for the prevention, management and care of diabetes mellitus. EMRO technical publications series 32 . Cairo: World Health Organization Regional
Office for the Eastern Mediterranean, 2006. http://whqlibdoc. who.int/e mro/2006/ 9789290214045_eng.pdf (accessed Aug 2009).

14 Lutfiyya MN, Patel YR, Steele JB, et al. Are there disparities in diabetes care? A comparison of care received by US rural and non-rural adults with diabetes. Prim Health Care Res Dev 2009; 10: 320-331.

15 National Diabetes Services Scheme. Young adults with diabetes: needs analysis. Canberra: Diabetes Australia, 2006. http://www.diabetesaustralia.com.au/PageFiles/1218/Young\% 20Adults\%20w\%20Diabetes\%20Needs\%20Ana lysis\%20Report.pdf (accessed Aug 2009).

16 Handelsman P, Craig ME, Donaghue KC, et al. Homogeneity of metabolic control in New South Wales and the Australian Capital Territory, Australia. Diabetes Care 2001; 24: 16901691.

17 National Collaborating Centres for Women's and Children's Health and Chronic Conditions. Type 1 diabetes: diagnosis and management of type 1 diabetes in children, young people and adults. Clinical guideline 15. London: National Institute for Clinical Excellence, 2004. http://
guidance.nice.org.uk/CG15 (accessed Sep 2009).

18 Wills CJ, Scott A, Swift PGF, et al. Retrospective review of care and outcomes in young adults with type 1 diabetes. BMJ 2003; 327: 260-261.

19 White NH, Cleary PA, Dahms W, et al. Beneficial effects of intensive therapy of diabetes during adolescence: outcomes after the conclusion of the Diabetes Control and Complications Trial (DCCT). J Pediatr 2001; 139: 804-812.

20 Scott L, Vallis TM, Charette M, et al. Transition of care: researching the needs of young adults with type 1 diabetes. Can J Diabetes 2005; 29: 203-210.

21 Svoren BM, Butler D, Levine BS, et al. Reducing acute adverse outcomes in youths with type 1 diabetes: a randomized, controlled trial. Pediatrics 2003; 112: 914-922.

22 Van Walleghem N, MacDonald CA, Dean HJ. Evaluation of a systems navigator model for transition from pediatric to adult care for young adults with type 1 diabetes. Diabetes Care 2008; 31: 1529-1530.

(Received 8 Sep 2009, accepted 28 Jun 2010) 